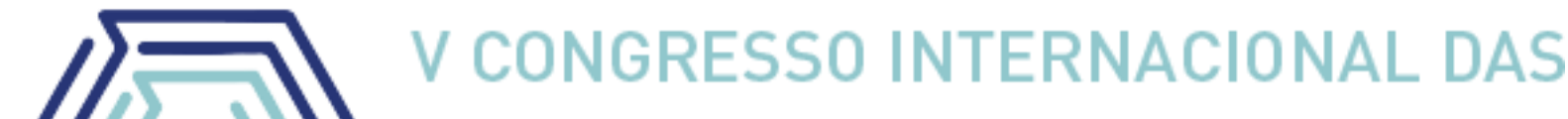 LICENCIATURAS COINTER - PDVL 2018
}

\section{SHOW DA QUÍMICA: UMA SEQUÊNCIA DE EXPERIMENTOS VISUAIS E INTERATIVOS}

\section{CHEMICAL SHOW: A SESSION OF VISUAL AND INTERACTIVE EXPERIENCES}

\section{Apresentação: Relato de Experiência}

Marconi dos Santos Ribeiro Júnior ${ }^{1}$; Adriana Pinto Ferreira ${ }^{2}$; Mileny Ferreira Nascimento $^{3}$; Lucas Rodrigues de Oliveira ${ }^{4}$; Alessandra Marcone Tavares Alves de Figueirêdo ${ }^{5}$.

\section{DOI: https://doi.org/10.31692/2358-9728.VCOINTERPDVL.2018.00318}

\section{Introdução}

Por ser considerada, por grande parte dos estudantes, uma disciplina abstrata, a Química é listada como de difícil aprendizado. Muitas vezes, isto é atribuído pela metodologia de ensino obsoleta utilizada pela maioria dos docentes. Para sanar tal problemática, faz-se necessário que o ensino dessa Ciência seja diferencial e promova, de maneira interativa, a fácil aquisição dos conhecimentos pelos discentes, mediado pelo docente.

Nessa perspectiva, uma das atividades que corrobora para uma edificação de um processo de ensino e aprendizagem é o "Show da Química - SQ", denominado como um meio interacional de experimentos apresentados de uma forma visual, que facilita a capacidade de captar, perceber e associar os conceitos químicos apresentados ao dia a dia. Esta ideia corrobora com Arroio et al (2006), em que destacam que os experimentos abordados nos laboratórios, em sala de aula ou em outros meios, despertam o interesse dos alunos, independente do nível escolar que estejam.

Portanto, este trabalho teve como objetivo apresentar um Show da Química interativo, ilustrando experimentos "chamativos" aos alunos do Ensino Médio e, ainda, observar o efeito e a influência deste tipo de atividade para a propagação da Química, se distanciando assim, do método tradicional de ensino.

\section{Relato de Experiência}

\footnotetext{
${ }^{1}$ Licenciatura em Química, IFPB Campus João Pessoa, marconijunior1@hotmail.com

${ }^{2}$ Licenciatura em Química, IFPB Campus João Pessoa, adrianaquimicaufpb@hotmail.com

${ }^{3}$ Licenciatura em Química, IFPB Campus João Pessoa, milenyferreira@live.com

${ }^{4}$ Licenciatura em Química, IFPB Campus João Pessoa, cadlucasrodrigues@hotmail.com

${ }^{5}$ Doutora em Química, IFPB Campus João Pessoa, alessandratavaresfigueiredo@ifpb.edu.br
} 
A experimentação tem um papel crucial na fundamentação de um fenômeno, ao se observar uma ação na prática cotidiana. Dessa maneira, considerando os fatores que a influenciam, podemos confirmar conhecimentos que até então eram simplesmente teóricos, pois a proximidade entre os conceitos científicos e os conceitos empíricos, faz com que o entendimento e aplicação de conteúdos teóricos, sejam mais elucidados.

Para a realização deste trabalho, foram utilizadas as metodologias de caráter quantitativo e qualitativo, assim como a participante. A última é conhecida como o compartilhamento do pesquisador com os papéis e hábitos dos integrantes de um determinado grupo social, durante certo período, tendo em vista observar acontecimentos que não ocorreriam ou seriam alterados na presença momentânea do pesquisador (LUDWIG, 2009).

Já abordagem quantitativa diz respeito aos dados mensuráveis por meio da utilização de recursos e técnicas estatísticas. Enquanto que, a abordagem qualitativa enfoca a visão sistêmica do problema ou objeto de estudo, isto é, tenta explanar toda realidade por intermédio do estudo da complexidade dos problemas sociopolíticos, econômicos, culturais, educacionais, e segundo determinadas peculiaridades de cada objeto de estudo (OLIVEIRA, 2008).

A atividade intitulada "Show da Química" foi realizada durante o primeiro semestre letivo de 2018, na escola privada de ensino regular Santa Dorotéia, localizada no município de João Pessoa, Paraíba, Brasil, sendo aplicada em conjunto com as turmas do $1^{\circ}$ ano (vinte e dois alunos) e $3^{\circ}$ ano (dez alunos), do Ensino Médio.

O SQ foi realizado com a apresentação de 3 (três) experimentos contextualizados (Camaleão, Varinha e Chope) ao cotidiano dos discentes, os quais retratavam grande efeito visual, dentre outros, que envolvia mudanças de coloração, aparecimento de chamas e desprendimento de gás. Tal atividade foi realizada pelos integrantes do Programa de Educação Tutorial - PET Química, do Instituto Federal da Paraíba - IFPB, Campus João Pessoa.

Um dos experimentos realizados foi à dissociação do peróxido de hidrogênio $\left(\mathrm{H}_{2} \mathrm{O}_{2}\right)$ por meio da catálise, no qual utilizou o iodeto de potássio (KI) como reagente catalisador apresentado na (Figura 1). O experimento denomina-se "Chope", que tem como referência a espuma de uma cerveja transbordando em um copo. Para tal experimento, foram utilizados os seguintes materiais/reagentes/vidrarias: detergente, peróxido de hidrogênio, iodeto de potássio e proveta. 
Figura 1: Realização da prática "Chope". Lado esquerdo, aluna voluntária e ao lado direito, o aluno PETiano bolsista. Fonte: Própria

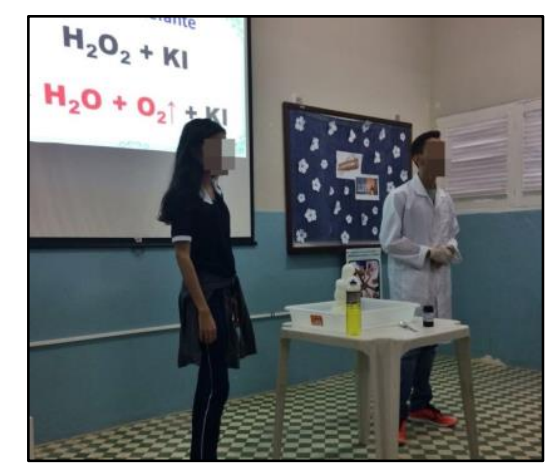

A princípio, na execução da prática, o PETiano responsável solicitou à aluna voluntária a colaborar na realização do experimento. Inicialmente, foi colocado $30 \mathrm{~mL}$ de peróxido de hidrogênio em uma proveta e acrescentou-se $10 \mathrm{~mL}$ de detergente neutro. Nesse momento, indagou-se ao público e a aluna colaboradora se a mistura dentro da proveta estava reagindo. Todos falaram que não. Logo após, adicionou-se um pouco de iodeto de potássio e observaram-se os resultados.

Após o término da prática, perguntou-se à voluntária e aos demais que estavam na plateia, se sabiam qual fator teria influenciado na aceleração da reação química. No primeiro momento, não souberam responder, sendo necessária a intervenção do PETiano para mediar o processo de ensino e aprendizagem. Posteriormente, a essa intervenção, os alunos começaram a entender o que tinha ocorrido.

$\mathrm{Na}$ explicação desse experimento, houve a utilização de uma metodologia contextualizada e interativa. De acordo com Atkins e Jones (2012, p. 596), o peróxido de hidrogênio quando em contato com a luz, se decompõe em água e oxigênio. Essa reação é lenta e discreta, que pode ser perceptível ao adicionarmos o detergente e o catalisador (KI), com essa adição observou-se a liberação do oxigênio que se prendeu ao detergente e formou a espuma, a formação de água e o catalisador presente no fim da reação, como consta na reação I mostrada:

$$
2 \mathrm{H}_{2} \mathrm{O}_{2(\mathrm{aq})}+\mathrm{KI}_{(\mathrm{s})} \longrightarrow 2 \mathrm{H}_{2} \mathrm{O}_{(\mathrm{aq})}+\mathrm{O}_{2(\mathrm{~s})}+\mathrm{KI}_{(\mathrm{s})} \quad \text { reação I }
$$

Esse mesmo experimento, também possibilitou trabalhar outros conceitos químicos, como a liberação ou absorção de calor de uma reação, denominada de exotérmica e 
endotérmica, respectivamente. Nesse sentido, foi pedido à voluntária que tocasse na proveta e averiguasse a temperatura que a mesma se encontrava. Ao verificar e comentar que estava quente, ela e os demais discentes responderam que se caracterizava em uma reação que liberava calor, chamada exotérmica.

Durante essa experimentação, os alunos do $3^{\circ}$ ano destacaram comentários como: Aluno 1: "Fica mais fácil entender com exemplos práticos"; Aluno 2: "Eles explicam bem detalhadamente, bem fácil de entender'. As duas práticas restantes, Camaleão e Varinha, seguiram a mesma metodologia.

Portanto, a partir de uma metodologia diferenciada, como o "Show da Química", pode-se notar que o público interagiu e participou de forma dinâmica, contextualizando os conceitos químicos com o cotidiano deles, corroborando para o favorecimento de uma aprendizagem substancial.

\section{Considerações}

A aproximação de conteúdos químicos teóricos à praticidade do cotidiano, se torna uma excelente alternativa para uma melhor compreensão, por grande parte dos discentes, de assuntos de difícil assimilação. E o uso de experimentos chamativos para elucidar essa proximidade se caracteriza como uma ferramenta crucial para a contextualização de conceitos e uma construção do processo de ensino e aprendizagem.

Assim sendo, a atividade "Show da Química" tem sido o carro chefe do PET Química IFPB há bastante tempo, visto que, apresenta uma excelente receptividade de toda comunidade escolar. Desse modo, sendo um ótimo recurso, pois utiliza uma abordagem dinâmica com uma grande interatividade entre discentes e PETianos, estimulando assim, o interesse pela Ciência, possibilitando a fácil compreensão dos conceitos químicos atrelados à experimentação, com isso, despertando a criticidade e formando cidadãos conscientes.

\section{Referências}

ARROIO et al. O Show da Química: Motivando o Interesse Científico. Quim. Nova, Vol. 29, No. 1, 173-178, 2006.

ATKINS, $P . W$. .jONES, L. Princípios de química: questionando a vida moderna e o meio ambiente. 5. ed. Porto Alegre: Bookman, 2012.

LUDWIG, Antonio Carlos Will. Fundamentos e Prática de Metodologia Científica. Petrópolis - RJ: Editora Vozes, 2009. 
OLIVEIRA, Maria Marly de. Como fazer pesquisa qualitativa. $2^{\mathrm{a}}$ edição. Petrópolis, RJ: Vozes, 2008. 